\title{
Integration of Theory of Constraints Thinking Process and Lean Production for Troubleshooting on a
} \section{Contractor}

\author{
Vitor Hugo Martins e Resende ${ }^{1}$ and Tatiana Gondim do Amaral ${ }^{2}$ \\ 1. School of Engineering, Pontifical Catholic University of Goiás, Goiânia 74605-010, Brazil \\ 2. Department of Civil Engineering, Federal University of Goiás, Goiânia 74605-220, Brazil
}

\begin{abstract}
The thinking process of TOC (Theory of Constraints) was an important consolidated tool to the systematization of the companies' necessities because of its competitive advantage. The lean thinking proposed by Taiichi Ohno and developed by Toyota Company has been tested and found effective in several production processes. This paper aims to propose a method of problem solving through the integration of the principles of lean thinking and the TPTOC (Thinking Process of the Theory of Constraints). The method was implemented on a civil contractor, using the research methodology and the action research. We concluded that, after the research, the core problem regarding the company is the technical failure of the administrative staff, which causes delay in the construction works and financial loss. We also concluded that the obstacles that could prevent the achievement of objectives are related to lack of a vision from senior management regarding financial return when investing in employee training. The goal was accomplished with the integration of two philosophies, TPTOC and lean. And only the tools proposed by Flávio Augusto Picchi were not enough for executing the action, so new lean actions were verbalized.
\end{abstract}

Key words: Exchange information, thinking process, lean thinking.

\section{Introduction}

The supply chain has two major flows, the materials and the information. In these flows, several factors contribute to the success or failure of the companies that are partial or are inserted in this chain.

To Bowersox et al. [1], the information flow is responsible for integrating the operation of the three major areas of the supply chain, which are customers, companies and the suppliers.

According to Christopher [2], information system is the mechanism, by which the complex flow of materials, parts, subset and finished products can obtain a service with a low cost if they are coordinated.

Bowersox et al. [1] commented that, within the different areas of logistics, there are different needs in actions with their respective order of importance. The

Corresponding author: Tatiana Gondim do Amaral, Ph.D., professor, research field: management in construction. E-mail: tatiana_amaral@hotmail.com. primary objective of managing the flow of information is to reconcile these differences in order to improve the performance of the chain.

It can be analyzed that some elements are part of the chain material from the perspective of information flow and realize the positive or negative impact which this flow causes: (1) Malfunction: The supplier or the transport company can be qualified or disqualified depending on the number of malfunction or faults of a material; (2) Standard Palletisation: The information of the standard palletisation according to the storage pattern of an enterprise can reduce the number of employees in the receiving area, and on the other hand, the failure or lack of information can take the company to increase the amount of this labor to perform services, such as re-palletisation.

In this perspective, the companies need to analyze their flow and identify possible system failure as a whole to remain competitive and to continue to make 
money.

According to Goldratt [3], the goal of all companies is to make money. But for the companies to achieve the established indicators and therefore reach the target, some management tools can be applied, such as the Ishikawa's diagram, the PDCA (Plan-Do-Check-Act) method, etc. Gupta and Boyd [4] said that, over time, the TOC (Theory of Constraints) has consolidated itself as a good theory in the management field. Klein and Debruine [5], however, considered that TOC evolved into a philosophy that goes beyond the factory floor.

This article differs, since it is proposing to use a new technique proposed by Goldratt [6] together with the principles of lean thinking.

\section{Methodology}

The methodology is classified as an action research, the purpose of which is to promote the dissemination of knowledge, promote the cycle of action research and integrate theory and practice.

According to Thiollente [7], this method meets the need of introduction of participatory methods in the organizational environment and enables close cooperation relationship between researchers and members of the organization, which are the characteristics required for this research. It is noteworthy that the action research and the thinking process of theories of constraints have similarity to pursue research and solve complex problems through the integration of several individual views, generating innovative solutions.

Kim et al. [8] said that the consolidation of the TOC happened since it was conceived as a method of identification, analysis and problem-solving.

The development of the research occurred through meetings between the governing body of the company, which is the focus of the study and the researcher; This was done through the use of the techniques proposed by TOC and the principles of lean production for the identification and problem-solving. The contact with the company's planning coordinator, which is responsible for construction works and for all the technical operations, was done through telephone and a meeting which was scheduled at the company.

At the first meeting, all the TOC's techniques and the principles of lean production were presented to the planning coordinator, responsible for construction works.

At the second meeting, the method proposed by this paper was applied at the meeting room using resources as paper and pen.

After the application of this technique, an interview with the company's planning coordinator, responsible for construction works, was conducted. The results are going to be presented at the conclusion of this paper.

\section{TPTOC (Thinking Process of Theory of Constraints)}

In the 1980s, TOC, proposed by Goldratt [9], revolutionized the foundations of business management.

According to Choe and Herman [10], the TOC evolved from the scheduling technique of operations to a management philosophy focused on a continuous improvement process. At the early stage of development, TOC's main focus was in the production context. In the TOC, every effort is directed to find the constraint or production bottleneck. In this sense, it seeks to analyze how to act in a way that the whole system works with the rhythm of the bottleneck and increases its efficiency. If the efficiency increases in a way that the process is no longer the bottleneck, it must return to the beginning of the analysis process.

According to Ref. [11], the following steps must be followed to apply the TOC:

(1) Identify the system constraints;

(2) Decide how to exploit the system constraints;

(3) Subordinate the rest of the previous decision;

(4) Lift the constraints; If in the previous steps, any constraint is changed, go back to the first step.

According to Goldratt and Cox [11], every system is 
governed by constraints, which, by definition, is any obstacle that prevents the system from achieving its goals, or in other words, it is the possible result called "global optimum".

The impression is that the variables or system problems are many, but Goldratt [6] stated that these problems are not independent. According to the author, among them, there is a strong link between cause and effect.

Therefore, the systems are governed by these constraints, but because of the complexities of these systems, few problems will influence globally, being only one or two, e.g., root problems, which is the cause of all the others [6]. Obviously, acting on only one or two problems is less laborious and more efficient than acting in several.

According to Cox and Spencer [12], the TOC seeks to answer in the following order, three main questions. Table 1 shows the questions.

\subsection{CRT (Current Reality Tree) (What to Change?)}

To Antunes [13], the aim of the CRT (Current Reality Tree) is the definition of the central problems found in their specific systems.

The procedures for the construction of the CRT are based on Ref. [14] and they are described below. The sequence illustrates some entities commonly found in the CRT in Ref. [15]:

(1) Make a list of approximately 5 10 UEs (undesirable effects);

(2) Find a cause-effect between at least two UEs, ask the question "Why does this UE happen?" and check if any other UE is the answer for this question. Thus, the first mentioned UE is the effect while the other is the cause, setting up a simple cause-effect relation. In general, a UE can be the cause of another UE and, at the same time, it can be the effect of a third one (effect-cause-effect relation);

(3) When the relation is perceived, the UE cause must be connected with an arrow from the UE to the effect;

(4) Search and solve any insufficiency, this is, when a UE per se is not enough to justify the cause of the following UE, as shown in Table 2. The insufficiency can be solved by finding another UE, included or not in the list, which are also causes of the UE;

(5) Read the tree from bottom to top, as follows: If the UE cause happens, UE occurs; When there is insufficient, the reading should be reversed: If UE cause A and B happen, UE happens;

(6) Scrutinize the relations of cause and effect and correct them whenever necessary;

(7) Check if it is not being discarded any fact that may seem trivial but can connect all them to form a

Table 1 Questions and tools of TPTOC (Thinking Process of the Theory of Constraints) [12].

\begin{tabular}{ll}
\hline Central questions & Tools \\
\hline What to change? & CRT (Current Reality Tree) \\
\hline \multirow{2}{*}{ What is it supposed to be changed into? } & CE (Clouds Evaporation) \\
\hline \multirow{2}{*}{ How to cause the change? } & FRT (Future Reality Tree) \\
\hline
\end{tabular}

Table 2 Consistency table of the CRT (current reality tree) [16].

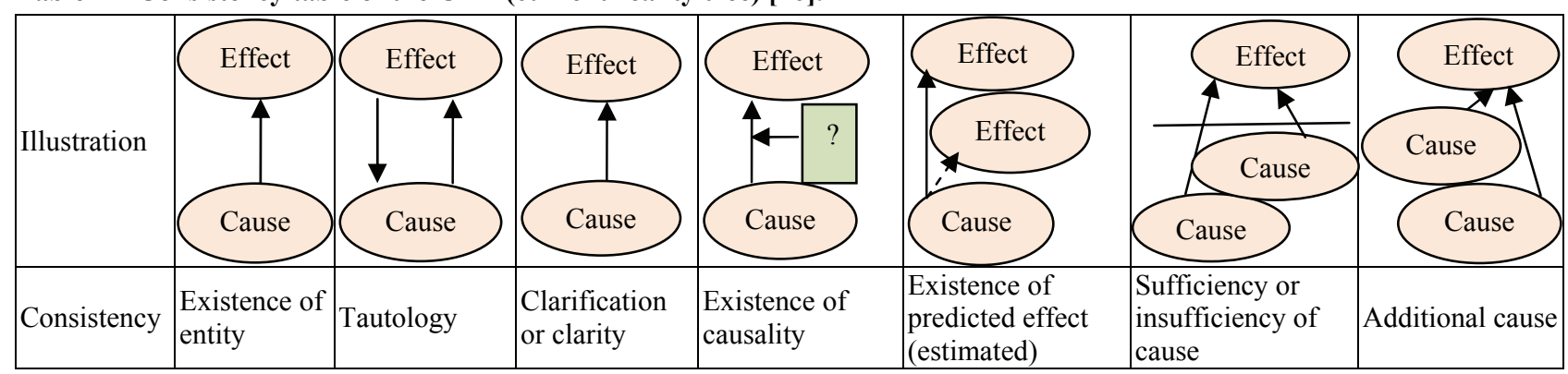


coherent framework. Often the trivialities allow impact solutions;

(8) Present the tree for other people, aiming to question the existing assumptions;

(9) Examine all entry points of the tree; Choose the one that contributes the most to the existence of the UE.

The connection of the UEs should be constructed by arrows, and to read the tree correctly, it is necessary to understand some consistencies. Table 2 shows the connections.

After performing the step of UEs' connection, it is possible to realize that there are some not caused by any other UE. This UE is different from the others due to the impact that it causes to the system as a whole and it is called "root problem".

\subsection{CE (Clouds Evaporation) (What Is It Supposed to Be Changed into?)}

According to Goldratt [6], after the first step is performed, by answering the question "What to change?", it is necessary to move to the next stage that is to answer "What is it supposed to be changed into?" in order to find the solution to the central problem, which is the system main constraint.

The two techniques used to achieve this goal are CE (Clouds Evaporation) and FRT (Future Reality Tree).

$\mathrm{CE}$ is the technique that seeks to verbalize unspoken assumptions and is directly linked to the central problem and, in general, these central problems originate from a conflict of position $[12,13]$.

The ongoing conflict is an opposition of ideas among people who are connected to the central problems. According to Goldratt [17], to problems that have easy solutions and do not show any kind of constraint, the solution has probably been implemented. On the other hand, if an easy solution has not been implemented yet, it is because there is a blockage. Therefore, to solve these problems, trade-off solutions between the divergent parts are necessary.

Trade-off solutions are understood as decisions are taken in consensus, favoring one of the presented positions that are conciliatory decisions. The TOC understands that, in these situations, there is always a simple and creative solution that breaks with the assumptions [5, 9, 15, 18].

The solution requires a decision, in which it is necessary to question the assumptions that define the confliction requirements. Goldratt [6] stated that, whenever a conflict is found, there is a clear sign that at least one of the assumptions is false.

The CE is the verbalization of creative solutions or "injections" that are capable of breaking paradigms and reach a win-win solution, in which one of the assumptions is removed and one side is chosen by mutual agreement. Fig. 1 represents CE.

\subsection{FRT (Future Reality Tree) (What Is It Supposed to Be Changed into?)}

As the name suggests, from this point, people start thinking and verbalizing future solutions in order to ensure the problem solution.

After the injection of CRT, the next step is to ensure the effectiveness of the raised solution. It is important to verify the effectiveness of the proposed solution (injection). The injection should be able to eliminate the undesirable effects and raise in its place DEs (desirable effects). For this, it uses the technique FRT (Future Reality Tree), by Hilgert [19].

The technique consists in creating another logical tree, using the analysis effect-cause-effect from the injection applied in the cloud evaporation. The process ends when the DEs and the initially identified UE in the CRT are connected.

At first, the construction of the FRT may be presented as a solution to all the verbalized problems at CRT, but FRT cannot eliminate all the UEs. To eliminate this problem, the creation of a negative subject is necessary by verbalizing and demonstrating what make injections unreal $[6,18]$. Table 3 describes the steps for construction of FRT. 


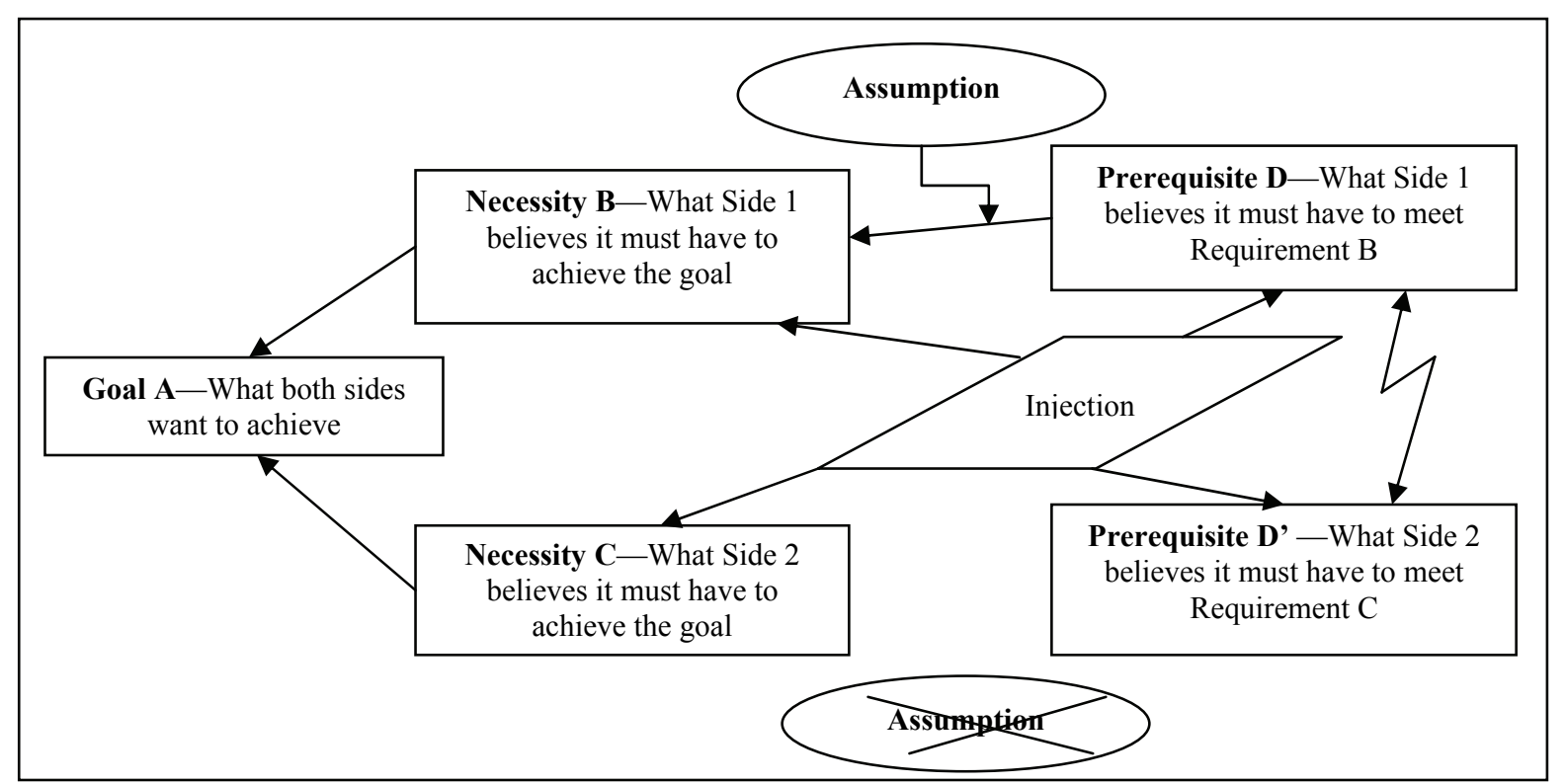

Fig. 1 CE (Cloud Evaporation) [16].

Table 3 Steps for the creation of the FRT (Future Reality Tree) [19].

\begin{tabular}{ll}
\hline Steps & Descriptions \\
\hline 1st step & Define the DEs (desirable effects), which usually opposes to UEs. \\
\hline 2nd step & $\begin{array}{l}\text { Create another tree from the injection applied for CE establishing effect-cause-effect relations. } \\
\text { 3rd step }\end{array} \begin{array}{l}\text { Verify if the DEs defined in Step 1 are obtained from the injection. These DEs are usually disposed on the top of the tree } \\
\text { analogously to the initial position of the UEs of the CRT. }\end{array}$ \\
\hline 4th step & $\begin{array}{l}\text { If the DEs previously established are not in the FRT, additional injections should be proposed until the number of } \\
\text { injections is able to take the cited DEs. }\end{array}$ \\
\hline
\end{tabular}

Table 4 Steps for the construction of the PT (Prerequisite Tree) [19].

\begin{tabular}{ll}
\hline Steps & Descriptions \\
\hline 1st step & Raise obstacles to the implementation of the injection. \\
\hline 2nd step & $\begin{array}{l}\text { To each obstacle, establish an IG (intermediate goal) capable of canceling it. Use the effect-cause-effect relation between } \\
\text { the obstacles and the IGs. }\end{array}$ \\
\hline 3rd step & Check if all the obstacles were eliminated by the IGs. \\
\hline 4th step & If it is identified in the obstacles, go back to Step 1. \\
\hline
\end{tabular}

\subsection{PT (Prerequisite Tree) (How to Cause the Change?)}

In any implementation, you can find obstacles that hinder the ultimate goal. Goldratt [20] stated that the ability that people who place obstacles should be used to positively serve as a base for the construction of the PT.

As Mackness and Rodigues [21] described, the PT starts from the injections and from the expected obstacles. Each obstacle generates an IG (intermediate goal) enough for overcoming it. Table 4 describes the steps for construction of PT.

\subsection{TT (Transition Tree) (How to Cause the Change?)}

Finally, after setting the intermediate goals, it is necessary to establish the actions to be performed. "The TT (Transition Tree) associates each intermediate goal to an action to be performed. The TT construction is the assembly of an action plan leading to the solution of the problem" [19].

Noreen [18] aimed to create an action goal plan that will eliminate the central problems.

Alvarez [15] stated that, this technique's name is justified by the fact that there is a transition from the initial state UEs to the DEs. 


\subsection{Lean Production Principles}

The lean principles have been studied and implemented in many companies of different branches. These principles are readings taken from the "lean manufacturing" philosophy created by Taiichi Ohno in half of the 20th century. The system was also known as TPS (Toyota Production System) for being applied in Toyota Industry [22].

The Lean philosophy has the search for waste elimination of the use of the technique JIT ("Just In Time") and automation as base, according to Ref. [22].

Picchi [23] conducted a survey on the lean thinking, analyzing concepts and thoughts of authors, like Womack and Jones [24], Spear and Bower [25] and Fujimoto [26]. From this work, Picchi [23] systematized the goals, principles, fundamental elements and examples of tools related to the lean thinking in a tabular form (Table 5).

\subsection{The Proposed Methodology (Which Lean Tool to Use?)}

The proposed methodology is to integrate the techniques of TPTOC (Thinking Process of theory of constraints) with the lean tools of the lean thinking by answering the question "Which lean tool to use?".

For each action that is verbalized, a lean tool must be selected for the change, using the full effectiveness of lean to transform reality.

According to Table 6, the question "Which lean tool will be applied?" should be verbalized and the answer should be a lean tool, as shown in Table 5 proposed by Picchi [23]. The proposed tool should be able to meet the proposed action verbalized as shown in Fig. 2.

\section{Application of the Model: Case Study in a Civil Construction Company}

The model was applied, and the first step was followed by asking the question "What to change?" (Fig. 3). The UEs were raised by planning coordinator of construction work. The sequence of links between UE is shown in Table 7.

After raising the UEs, the verbalization started in order to find the central problem.

Table 5 Overview of connections [23].

\begin{tabular}{|c|c|c|c|}
\hline Goal & Principles & Fundamental elements & Examples of tools \\
\hline \multirow{9}{*}{$\begin{array}{l}\text { 1. Continuously } \\
\text { improve the } \\
\text { competitiveness; } \\
\text { 2. Eliminate waste; } \\
\text { 3. Meet costumers' } \\
\text { requirements in relation } \\
\text { to variety, quality, } \\
\text { quantity, time and price }\end{array}$} & \multirow[t]{2}{*}{ Value } & $\begin{array}{l}\text { Product/service package of } \\
\text { expanded value }\end{array}$ & Planned variety of products \\
\hline & & Reduction of lead time & Concurrent engineering \\
\hline & Value stream & $\begin{array}{l}\text { High added value in the } \\
\text { extended enterprise }\end{array}$ & $\begin{array}{l}\text { 1. Value stream mapping; } \\
\text { 2. Partnership with suppliers }\end{array}$ \\
\hline & \multirow[t]{2}{*}{ Flow } & Flow production & $\begin{array}{l}\text { 1. Working cells; } \\
\text { 2. Small lots; } \\
\text { 3. TPM (total productive maintenance); } \\
\text { 4. Quality at the source; } \\
\text { 5. Poka-yoke (device foolproof) }\end{array}$ \\
\hline & & Standardized work & $\begin{array}{l}\text { 1. Graph balancing of the operator; } \\
\text { 2. Visual management }\end{array}$ \\
\hline & \multirow{2}{*}{ Pull } & JIT production and delivery & $\begin{array}{l}\text { 1. Takt time (production rhythm); } \\
\text { 2. Kanban; } \\
\text { 3. Leveling production }\end{array}$ \\
\hline & & Flexible resources & $\begin{array}{l}\text { 1. Fast set-up; } \\
\text { 2. Flexible equipments; } \\
\text { 3. Multifunctionality of operators }\end{array}$ \\
\hline & \multirow[b]{2}{*}{ Perfection } & Fast and systematic learning & $\begin{array}{l}\text { 1. Self-managing teams; } \\
\text { 2. Five whys; } \\
\text { 3. } 5 \mathrm{~S} \text { program }\end{array}$ \\
\hline & & Common focus & $\begin{array}{l}\text { 1. Commitment of the company's management with employees; } \\
\text { 2. Training everyone in the company and the suppliers in the } \\
\text { Lean principles and tools; } \\
\text { 3. Simplicity in communication }\end{array}$ \\
\hline
\end{tabular}


Table 6 Steps to the proposed methodology.

\begin{tabular}{ll}
\hline Central questions & Tools \\
\hline What to change? & CRT (Current Reality Tree) \\
\hline \multirow{2}{*}{ What is it supposed to be changed into? } & CE (Clouds Evaporation) \\
\hline How to cause the change? & FRT (Future Reality Tree) \\
\hline & PT (Prequisite Tree) \\
& TT (Transition Tree) \\
Which lean tool to use? & Variety of products; concurrent engineering; value stream mapping; partnership; \\
& production cells; lots reduction; TPM; quality at the source; Poka-yoke; chart balancing; \\
& visual management; Takt-time; Kanban; leveling production; fast set-up; flexible \\
& equipments; multifunctionality; self-managing; five whys; suggestion program; 5S \\
& program; board of director's commitment; training; simplicity in communication \\
\hline
\end{tabular}

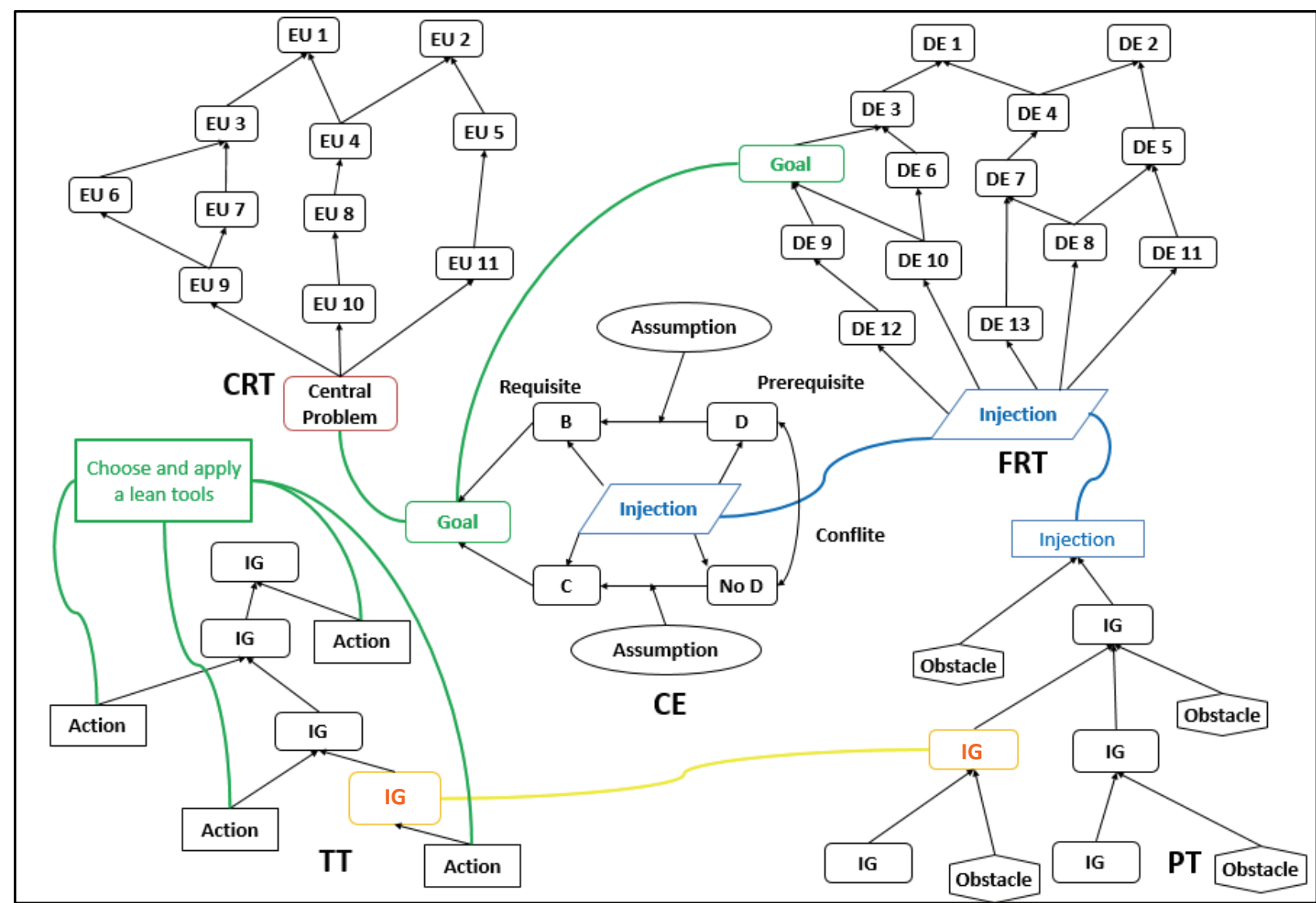

Fig. 2 Scheme proposed by the author [16].

\begin{tabular}{|c|c|c|c|c|c|}
\hline $\begin{array}{c}\text { Technical staff } \\
\text { of administrative } \\
\text { staff } \\
1\end{array}$ & $\begin{array}{l}\text { Delay in signing } \\
\text { the financing } \\
2\end{array}$ & $\begin{array}{c}\text { Delay in the } \\
\text { construction } \\
\text { work } \\
3\end{array}$ & $\begin{array}{l}\text { High cost of the } \\
\text { construction } \\
\text { work } \\
4\end{array}$ & & $\begin{array}{l}\text { Lack of knowledge } \\
\text { regarding the } \\
\text { project's scope } \\
5\end{array}$ \\
\hline $\begin{array}{l}\text { Failure in } \\
\text { scheduling } \\
\text { tasks } \\
6\end{array}$ & $\begin{array}{c}\text { Lack of project: } \\
\text { executive; architectural; } \\
\text { detailing } \\
7\end{array}$ & $\begin{array}{c}\text { Deficient } \\
\text { budgets } \\
8\end{array}$ & $\begin{array}{l}\text { Low quality of } \\
\text { the provided } \\
\text { services } \\
9\end{array}$ & $\begin{array}{c}\text { Rework } \\
10\end{array}$ & $\begin{array}{l}\text { Low } \\
\text { productivity } \\
11\end{array}$ \\
\hline
\end{tabular}

Fig. 3 Verbalization of UEs (undesirable effects). 


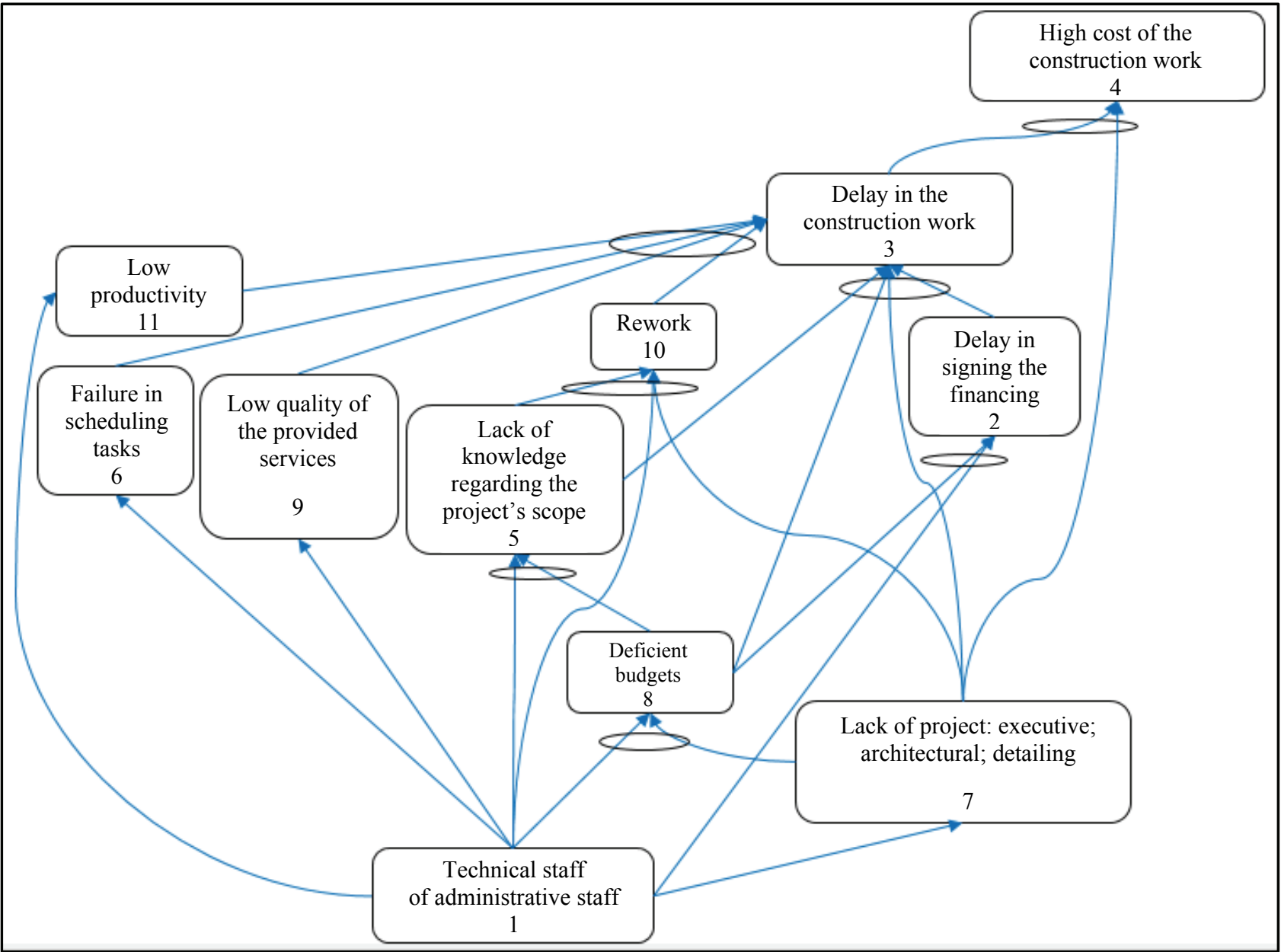

Fig. 4 CRT (Current Reality Tree).

Table 7 Verbalization sequence for the CRT (Current Reality Tree).

\begin{tabular}{ll}
\hline Verbalization & Sequence of UEs (undesirable effects) \\
\hline 1st & $1,2,3$ and 4 \\
2nd & 1,7 and 4 \\
3rd & $1,7,3$ and 4 \\
4th & $1,7,10,3$ and 4 \\
5 th & $1,8,2,3$ and 4 \\
6th & 8,3 and 4 \\
7th & $1,5,10,3$ and 4 \\
8th & 5,3 and 4 \\
9th & $1,9,3$ and 4 \\
10 th & $1,6,3$ and 4 \\
11 th & $1,11,3$ and 4 \\
\hline
\end{tabular}

After the verbalization and the construction of the CRT, there was a consensus between the coordinator and the researcher that the main problem was a technical failure of the administrative staff, as shown in Fig. 4.
After building the CRT, the second step was to answer the question "Why change?" using CE and the FRT.

In the CE construction (Fig. 5), the objective was verbalized as to ensure qualified administrative staff.

These were the requirements verbalized so that the objective will be accomplished:

- "Hiring more qualified professionals" in the first segment;

- "Qualify the current administrative staff" to the second branch.

The verbalization of the prerequisites required condition to achieve the prerequisites as:

- It requires the investment in good professionals;

- We need to implement an organizational development culture within the company.

The existence of a conflict is evidenced by the difference among the prerequisites. 
In another step, assumptions was verbalized that are sustaining the relationship in the diagram. The first branch "hiring qualified professionals ensures good results" and the second branch "qualify the current administrative staff' create a culture of motivation and loyalty to the company.

The first support may not be true in the long term and the assumption that hiring good professionals in a company without an organizational culture of development can not guarantee the motivation of hired professional broke the conflict, thereby, applying the called "injection", Fig. 5 illustrates the CE.

The injection of CE served as the starting point, as shown in Fig. 6. The question "Why change?" required for the construction of the FRT was verbalized, where UEs have been verbalized, as well as DEs. According to the verbalizations of DEs, the expected end result was the "reduction in the cost in construction works", as shown in Fig. 6.

Finally, the question "How to cause the change?" was verbalized. The first tool used to respond was the PT. The injection of CE, as shown in Fig. 5, also served as the starting point to build the PT.

The first verbalized obstacle was "the board understands the implementation as cost." This barrier is broken with the IO (intermediate objective): “changing the view of the company's board". So it was verbalized that the board understood it as cost because there is an obstacle "implementation gain is not measured". To break the barrier, it was verbalized the OI "measuring the gain with the implementation of Organizational Development Department". Finally, it

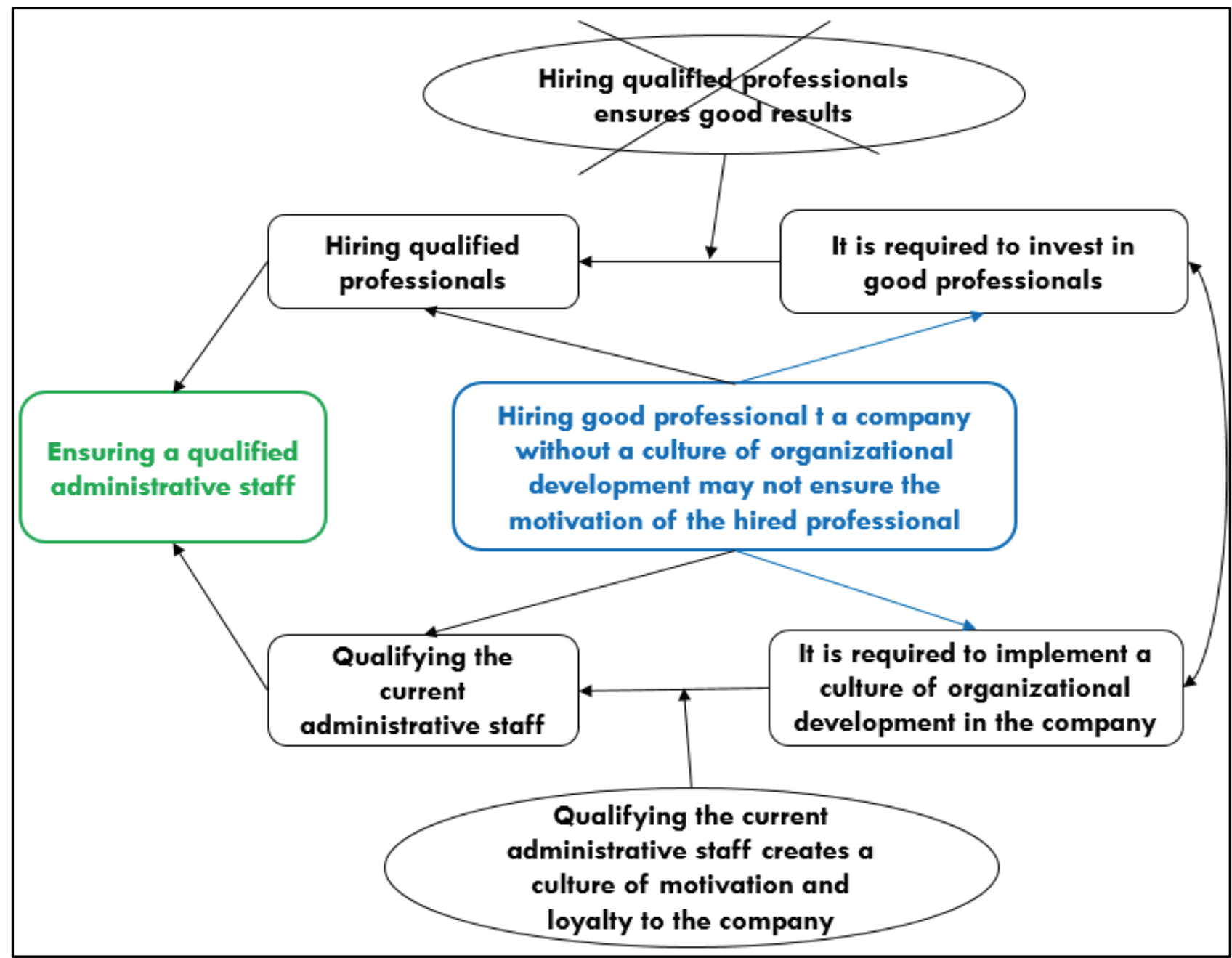

Fig. 5 CE (Clouds Evaporation). 


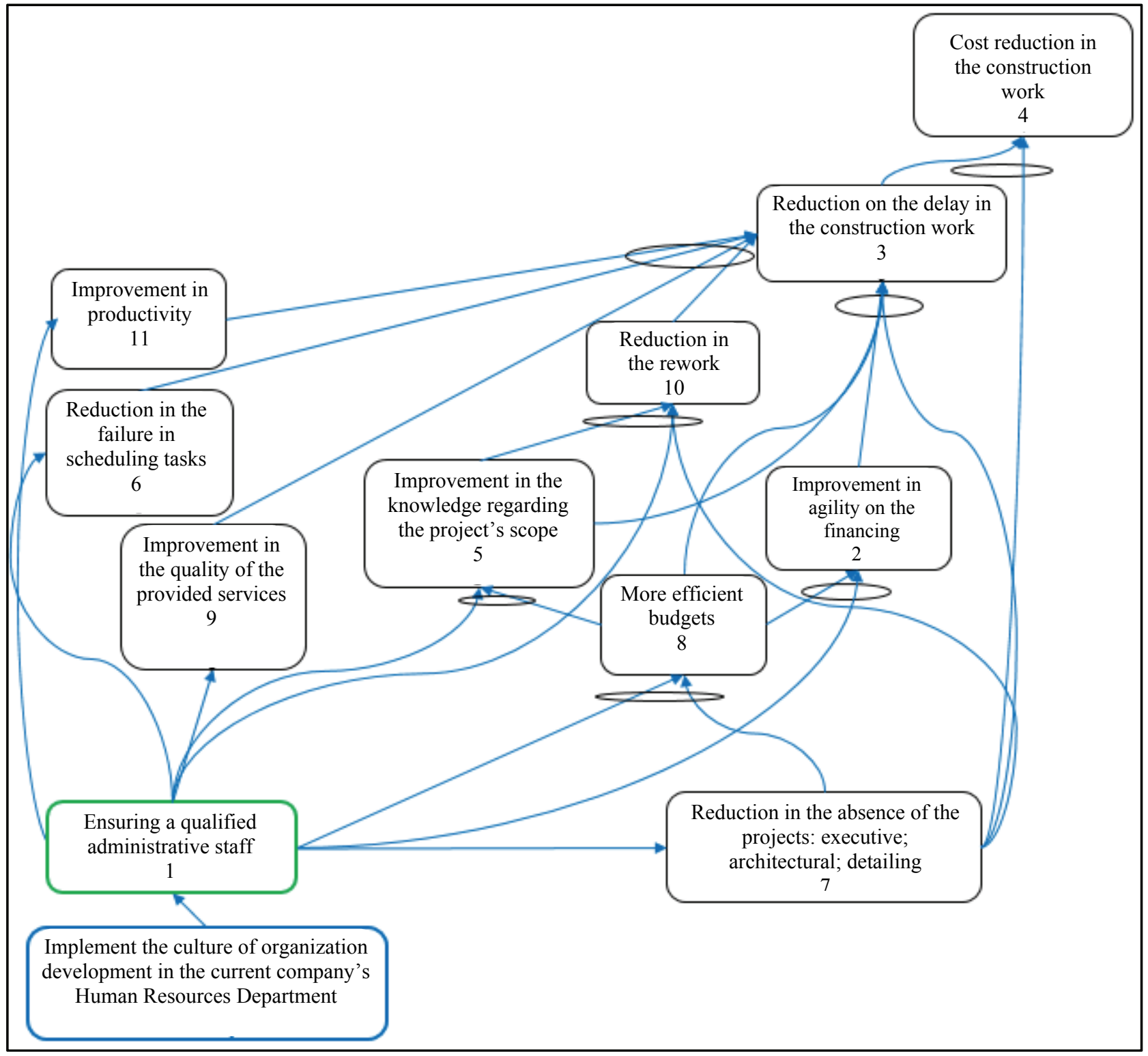

Fig. 6 FRT (Future Reality Tree).

was verbalized the obstacle: "lack of skilled manpower in the Human Resources Department". To break this obstacle, the IO was verbalized: "qualify the administrative staff for implementation of organizational development and measurement of gains". Fig. 7 shows prerequisites.

To finish the application of the technique, the last tool applied was the TT that seeks to answer the question "How to cause the change?" from the first IO.

Fig. 8 shows the TT.

Therefore, all the technique steps have been applied causing the interaction of trees, as shown in
Fig. 9:

After the construction of all the trees, it was then verbalized the central question of research proposal: "Which lean tool will be applied?".

In Table 5, proposed by Picchi [23], the verbalizations indicated that the most appropriate tools for action are:

- company's board of directors commitment to employees;

- training for all in the company and suppliers about the lean principles and tools;

- simplicity in communication. 


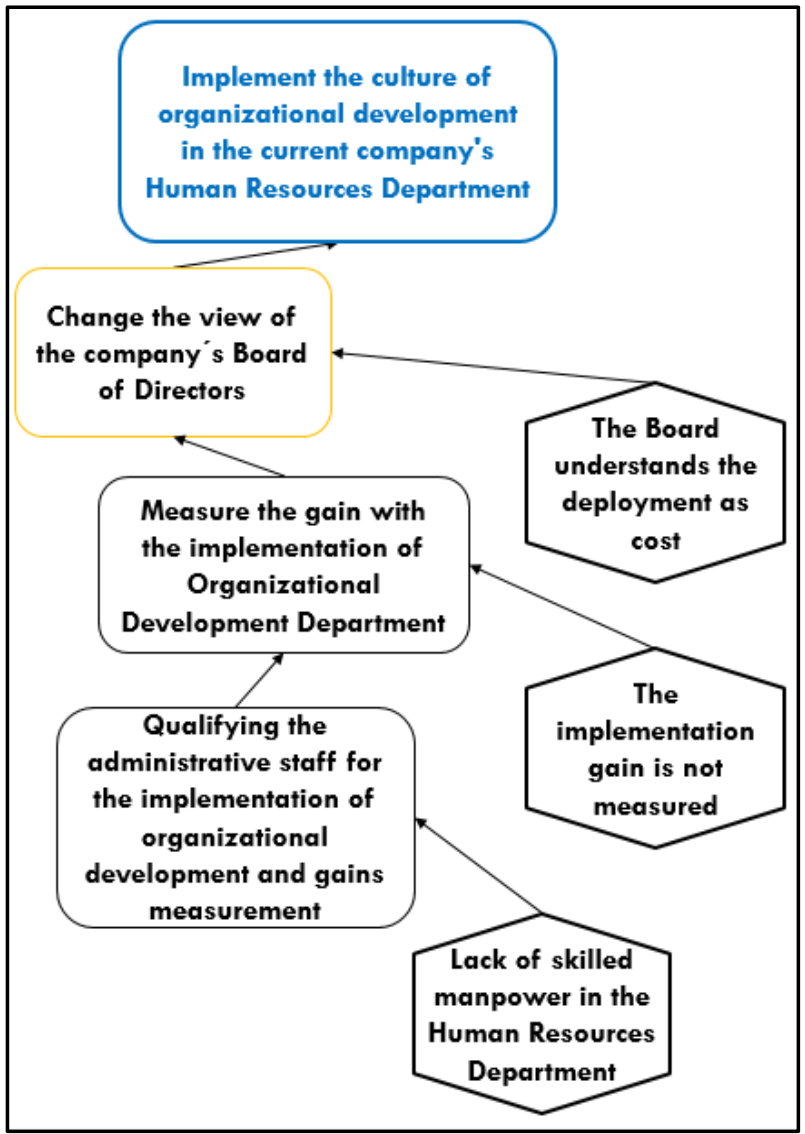

Fig. 7 PT (Prerequisite Tree).

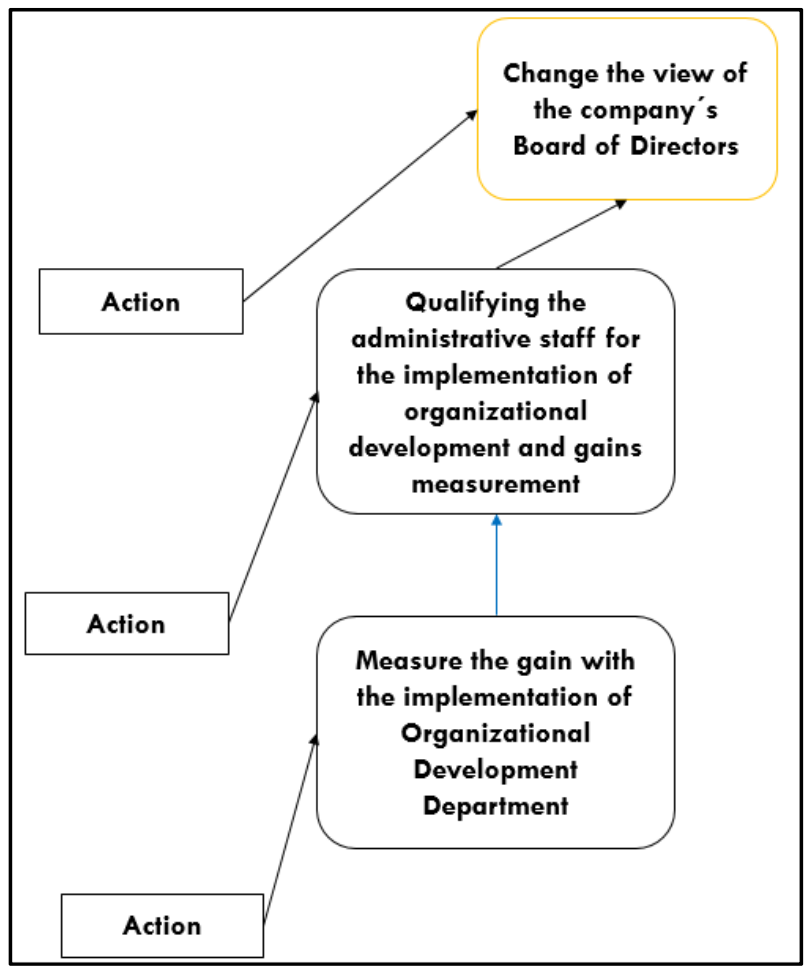

Fig. 8 TT (Transition Tree). 


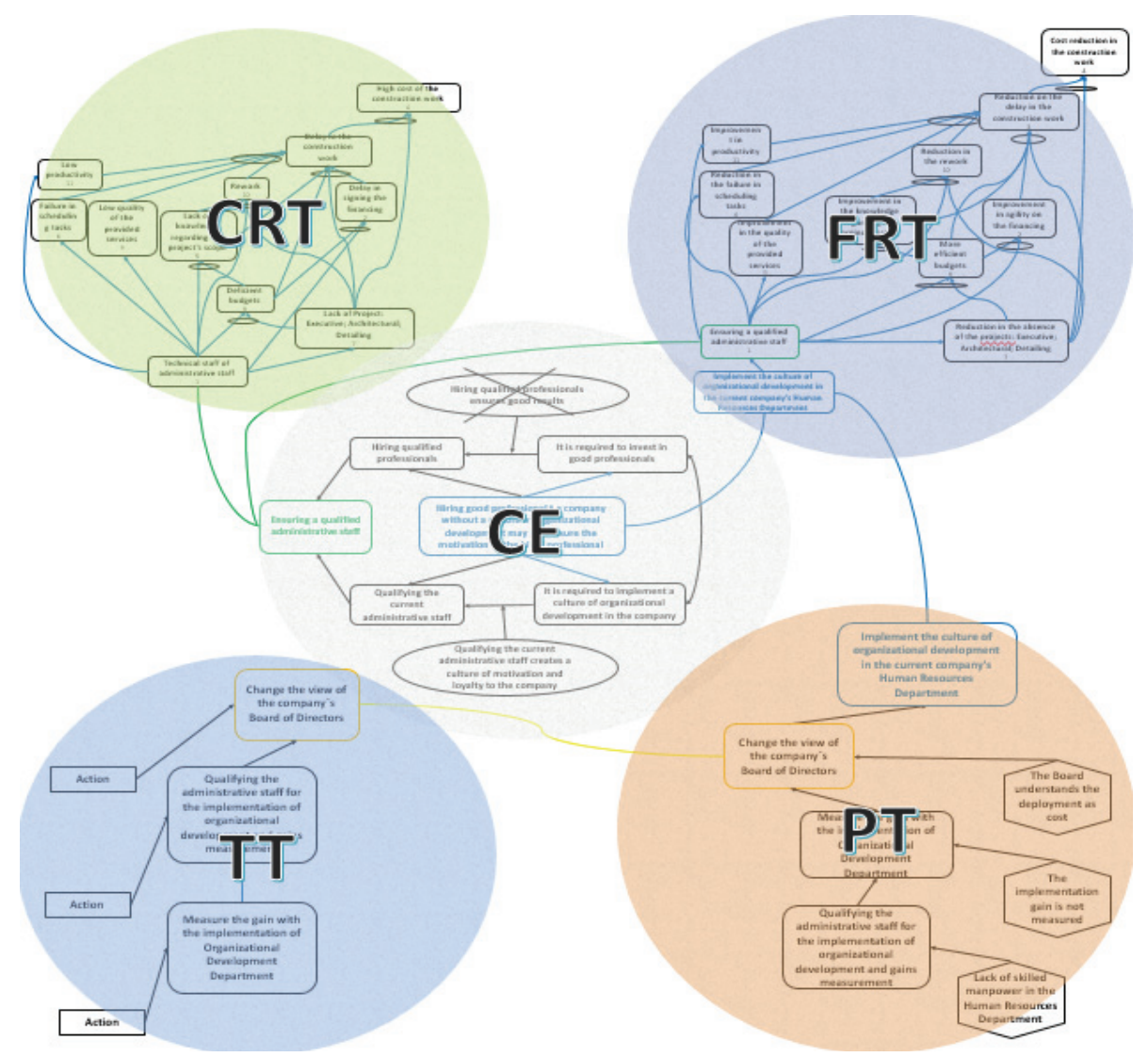

Fig. 9 Integration of all trees.

These tools are categorized with the key element of common focus and the principle of perfection.

When evaluating Table 5, we verified that Picchi [23] present "consistently meet customer requirements in variety, quality, quantity, time and price" as one of the goals of lean tools. Considering this, it was then verbalized that the application of tools can contribute to the elimination of the two main effects of the CRT: "delay in construction work" and "high cost of the construction work".

After this verbalization, it was noted specifically that only the tools were not able to be transformed into executable actions. So a new verbalization with lean actions was proposed by the authors, in order to contribute to the tools application. Fig. 10 has the verbalization leans tools and actions, integrating them with the TT.

Finalizing the construction process of the logic tree and with the proposed use of lean tools, the result is shown in Fig. 11.

\section{Conclusions}

The researchers found that, for the application of the proposed method, it would initially require a review and understanding of the topic for the harmonization of concepts and procedures.

The application of the method has a low cost of implementation but requires the availability of time for reflection on the causes and effects of the analyzed problems. The method has achieved its objectives as a method for identification of problems and use of the principles of lean production, as well as a troubleshooting by integrating the TPTOC.

With the construction of the trees, one can see that a central problem can trigger several side effects, the main of which were related to the time and cost in the case of this research. All these effects, as a result of the main problem, were the technical failure of the administrative staff.

It can be concluded with the construction of the trees 


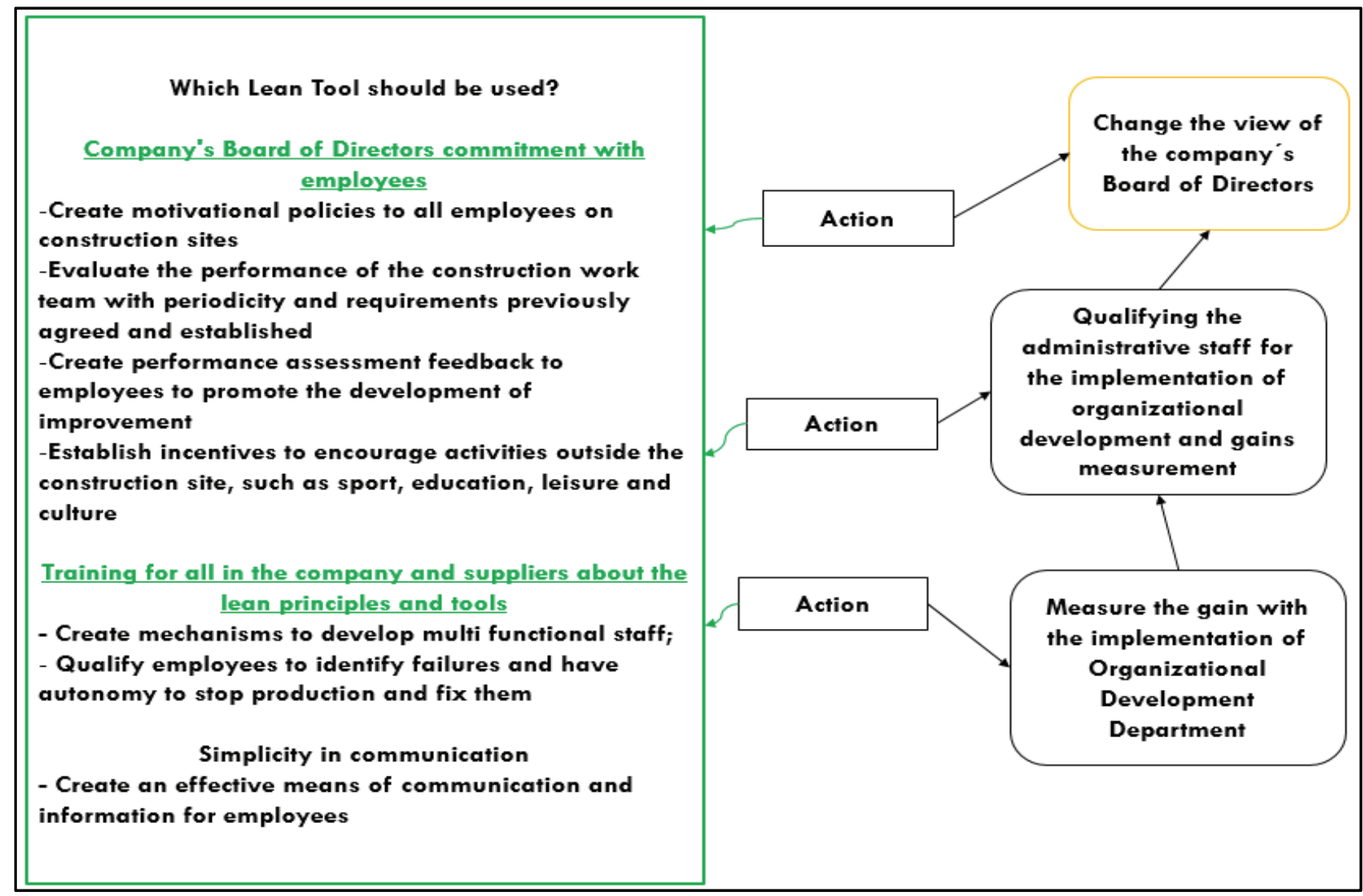

Fig. 10 Result of the application of the proposed method.

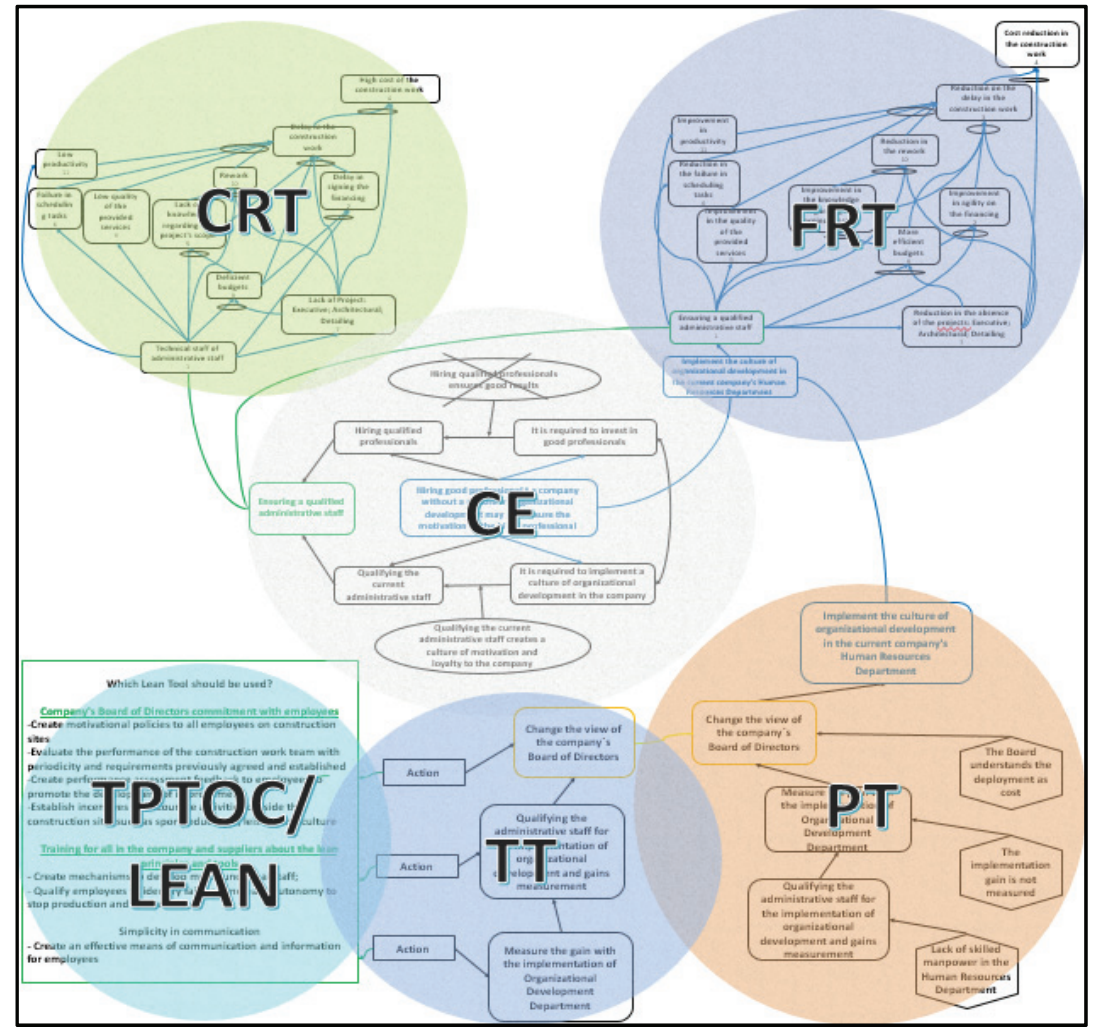

Fig. 11 Result of the application of the proposed method. 
objectives are related to lack of a vision of senior management regarding financial returns when investing in the training of employees.

The conditions for success of this integration which are related to the use of lean tools as a means of customer service, specifically in the case study, might be able to eliminate the effects of delay and high cost.

It can also be concluded that the TPTOC is a method that can identify the main problem of a company and generate actions that can eliminate this problem.

As a contribution, the research presents the integration of two philosophies: TPTOC and lean thinking, in which it was required to verbalize lean actions more specific and explanatory to be implemented to improve the fulfillment of so-called step of "action" in the TT.

\section{References}

[1] Bowersox, D. J., Closs, D. J., and Cooper, M. B. 2002. Supply Chain Logistic Management. Blacklick: McGraw-Hill, International Edition.

[2] Christopher, M. 2001. Logistics and Supply Chain Management: Strategy for Reducing Costs and Improving Service. São Paulo: Pioneira.

[3] Goldratt, E. M. 1991. The Haystack Syndrome: Sifting Information Out of the Data Ocean. São Paulo: Educator.

[4] Gupta, M. C., and Boyd, L. H. 2008. "Theory of Constraints: A Theory for Operations Management." International Journal of Operations \& Production Management 28 (10): 991-1012.

[5] Klein, D. J., and Debruine, M. 1995. "A Thinking Process for Establishing Management Policies." Review of Business 16: 31-7.

[6] Goldratt, E. M. 2004. It's Not Luck. São Paulo: Educator.

[7] Thiollent, M. 2000. Methodology of Action Research. São Paulo: Cortez.

[8] Kim, S., Mabin, V. J., and Davies, J. 2008. "The Theory of Constraints Thinking Processes: Retrospect and Prospect." International Journal of Operations \& Production Management 28 (2):155-84.

[9] Goldratt, E. M. 1994. It's Not Luck. New York: North River Press.

[10] Choe, K., and Herman, S. 2000. "Using Theory of Constraints Tools to Manage Organizational Change: A Case Study of Eupripa Labs." In Proceedings of 8th
International Journal of Management \& Organizational Behaviour, 540-58.

[11] Goldratt, E. M., and Cox, J. 1993. A Meta. 3rd ed. São Paulo: Educator.

[12] Cox, J., and Spencer, M. S. 2002. Handbook of Theory of Constraints. Porto Alegre: Bookman.

[13] Antunes, J. A. V., Klippel, M., Koetz, A. L., and Lacerda, D. P. 2004. "Critical Issues about the Theory of Constraints Thinking Process-A Theoretical and Practical Approach.” Presented at 15th POMS (Production and Operation Management Society), Cancun, Mexico.

[14] Azevedo, M. H. 2000. "Characteristics, Production and Use of Biogas from Organic Waste." Master thesis, Universidade Federal do Rio Grande do Sul, Porto Alegre, Brazil.

[15] Alvarez, R. R. 1996. "Development of a Comparative Analysis of Methods of Identification, Analysis and Troubleshooting." Master thesis, Universidade Federal do Rio Grande do Sul, Porto Alegre, Brazil.

[16] Lacerda, D. P., and Rodrigues, L. H. 2007. "Process of Restriction Theory of Thought: An Approach to Understanding, Learning and Action on Complex Problems." Perspectives in Management and Knowledge 1 (2): 59-76.

[17] Goldratt, E. M. 1990. What Is the Thing Called Theory of Constraints and How Should It Be Implemented?. New York: North River Press.

[18] Noreen, E., Smith, D., and MacKey, J. T. 1995. The Theory of Constraints and Its Implications for Management Accounting. Massachusetts: North River Press.

[19] Hilgert, C. M. T. 2000. "Proposal for a Decision Making Method Using the Theory of Constraints for Production Systems." M.Sc. thesis, Universidade Federal do Rio Grande do Sul, Porto Alegre, Brazil.

[20] Goldratt, E. M. 1993. Introduction of the Theory of Constraints through Application to Marketing and Sales. Berkshire: Avraham Y. Goldratt Institute.

[21] Mackness, J., and Rodrigues, L. H. 1995. A Thinking Process for Managing Change. Lancaster: Lancaster Publisher.

[22] Ohno, T. 1988. Toyota Production System: Beyond Large-Scale Production. New York: Productivity Press.

[23] Picchi, F. A. 2003. "Application Opportunities of Lean Thinking in Construction." Journal Built Environment 3 (1): 7-23.

[24] Womack, J. P., Jones, D. T., and Ross, D. 2004. The Machine that Changed the World: Based on the Massachusetts Institute of Technology Study on the Future of the Automobile. 10th ed. Rio de Janeiro: Elsevier Press. 


\section{Production for Troubleshooting on a Contractor}

[25] Spear, S., and Bowen, H. K. 1999. "Decoding the DNA of Toyota Production System.” Harvard Business Review 77 (5): 96-106.
[26] Fujimoto, T. 1999. The Evolution of a Manufacturing System at Toyota. New York: Oxford University Press. 